\title{
A produção do conhecimento sobre sala de aula invertida no ensino de Física: um olhar sobre a pós-graduação brasileira
}

\author{
José Diego Silva Gomes ${ }^{1}$ \\ Albino Oliveira Nunes ${ }^{2}$ \\ Albano Oliveira Nunes ${ }^{3} \mathrm{C}$ \\ ${ }^{1}$ Universidade do Estado do Rio Grande do Norte (UERN); ${ }^{2}$ Instituto Federal de Educação Ciência e Tecnologia \\ do Rio Grande do Norte; ${ }^{3}$ Universidade Federal do Ceará (UFC), Brasil
}

Resumo. A emergência das metodologias ativas no contexto da educação básica e superior tem, aos poucos, transformado a realidade educativa. Nelas o papel dos estudantes torna-se ainda mais pronunciado, invertendo a lógica de transmissão de conhecimento do ensino tradicional. É dentro desse contexto que no presente trabalho busca-se compreender o avanço sobre as pesquisas em Sala de Aula Invertida (SAI) no ensino de física brasileiro. Para tanto, realizou-se uma busca no Catálogo de Teses e Dissertações da Capes, obtendo doze textos que abordavam a estratégia. Os trabalhos foram analisados segundo a análise de Conteúdo de Bardin (2002) e o auxílio do software de análise textual Iramuteq 0.7 alfa 2. Os resultados demonstram uma concentração de pesquisas ao nível de mestrado profissional, com ênfase no ensino médio e concentradas nas regiões Sul e Sudeste. Sobre o conteúdo das dissertações percebe-se que há um forte indício de pesquisas de intervenção pedagógica com ênfase nas questões em dois grupos de interesse de investigação: um primeiro que visa compreender o ensino e outro que visa compreender a aprendizagem baseada na estratégia.

Palavras-chave: sala de aula invertida; estado da arte; metodologias ativas; ensino de Física; pósgraduação, flipped classroom.

La producción de conocimiento sobre el aula invertida en la enseñanza de la Física: una mirada a los cursos de postgrado brasileños

Resumen. La aparición de metodologías activas en el contexto de la educación básica y superior ha transformado gradualmente la realidad educativa. En estas, el papel de los alumnos se acentúa aún más invirtiendo la lógica de transmisión de conocimientos de la enseñanza tradicional. Es en este contexto en el que el presente trabajo trata de comprender los avances en la investigación sobre el Aula Invertida (All) en la enseñanza de la física en Brasil. Para ello, se realizó una búsqueda en el Catálogo de Tesis y Disertaciones de Capes, obteniendo doce textos que abordaban dicha estrategia. Los trabajos se analizaron según el análisis de contenido de Bardin (2002) y con la ayuda del software de análisis textual Iramuteq 0.7 alpha 2. Los resultados muestran una concentración de investigaciones en los posgrados de maestrías profesionales, con énfasis en la educación secundaria y concentrada en las regiones del Sur y del Sudeste. Sobre el contenido de las disertaciones se percibe que hay una marcada tendencia en investigaciones de intervención pedagógica con énfasis en dos grupos de interés: uno que apunta a comprender la enseñanza, y otro que apunta a comprender el aprendizaje basado en estrategias.

Palabras clave: aula invertida; estado del arte; metodologías activas; enseñanza de la física; posgrado; flipped classroom.

The production of knowledge about flipped classroom in physics teaching: a look at Brazilian post-graduation courses

Abstract. The growth of active methodologies in the context of primary and higher education has, slowly, transformed educational reality. In those methodologies, the students' role becomes even more pronounced, inverting the logic of knowledge transfer of traditional teaching. It is within this context that the present work aims to understand the advancement on the research concerning the Flipped Classroom (FA) method in the teaching of Physics in Brazil. For such, it was conducted a search on the Capes' Theses and Dissertations Catalogue, obtaining twelve text that approached the strategy. The works were analyzed according to the Bardin Content analysis (2002) and with the support of the text analysis software Iramuteq 0.7 alfa 2. The resulsts show a cluster of research at Masters degree level, with enphasis on High School education, and concentrated in the South and Southeast regions. Concerning the content of of those dissertations, it is noticeable that there is strong indicative of pedagogical intervention research with enphasis on the questions in two investigation interess groups: the first one, that aims to understand the teaching process; and the second, that aims to understand the learning based on this strategy.

Keywords: flipped classroom; state of the art; active methodologies; physics teaching; postgraduate education. 


\section{Introdução}

Uma metodologia que vem ganhando destaque e uma grande base de estudos na literatura como proposta de melhoria e aprimoramento do ensino contemporâneo é a que conhecemos como Sala de Aula Invertida (SAI), do inglês Flipped Classroom. Tendo como definição literal o que seria tradicionalmente feito em sala de aula, agora é executado em casa, e o que seria tradicionalmente feito como trabalho de casa, agora é realizado em sala de aula, dessa forma, pode-se dizer que existem elementos de metodologias ativas, visto que os papeis do professor e do aluno também são modificados (Berbel, 2011; Morán, 2015; Bacich \& Morán, 2018), onde o aluno ganha um papel muito mais ativo para sua trajetória formativa. Aaula invertida ganhou notoriedade e bastante reconhecimento com os trabalhos dos americanos Jonathan Bergman, Karl Fisch e Aarom Sans, realizados a partir de 2007, os quais tiveram o objetivo de usar o melhor dos recursos presenciais e virtuais para facilitar a aprendizagem dos estudantes (Bergman \& Sams, 2016; Fisch, 2010; Araújo, 2019), buscando tornar a aprendizagem mais significativa.

Com o avanço da globalização, modernização e tecnologia, a preocupação dos educadores com o aluno do século XXI se torna ainda mais notável, já que estes alunos não se sentem mais confortáveis estando sentados de forma passiva em uma sala de aula por horas e utilizando, possivelmente, um método mecânico de aprendizagem, havendo intervenções somente quando necessário ou ainda somente em um momento de permissão por parte do doecente. Em contrapartida, a metodologia da Sala de Aula Invertida (SAI) traz em sua proposta o professor como mediador do ensino-aprendizagem, tornando o aluno peça fundamental nesse processo, proporcionando, assim, uma interação mais significativa entre professores e alunos e entre os próprios discentes, tornando-se uma solução aceitável e satisfatória (Bergman \& Sams, 2016), dado o contexto em que estamos vivendo.

Para muitos autores, como Mazur (2015) e Suhr (2016), tal método procura modificar o papel do aluno fazendo sua transição de um aluno passivo para ativo, aprimorando seu senso de responsabilidade em relação aos conteúdos abordados e quanto ao seu próprio papel no processo conduz a sua formação, não cabendo ao professor, portanto, a transmissão de conceitos, mas sim uma organização de sequências de atividades que partem de situações-problema que levam os alunos a desenvolver e buscar soluções criativas em grupo.

Adaptações envolvendo a SAI, como por exemplo, usar a sala de aula invertida adaptada ao modelo de motivação ARCS de Keller (Aşiksoy \& Özdamli, 2015) vem mostrando que grandes resultados podem ser obtidos para o ensino de Física, gerando um aumento motivacional por parte dos alunos, verificando opiniões positivas sobre a abordagem de sala de aula invertida.

Além de servir como uma adaptação às aplicações de teorias existentes, a SAI tem como principal fundamento avaliar desempenho dos alunos, analisando suas atitudes e abordagens, em relação ao curso de física (Şengel, 2014), mostrando-se eficaz por partes dos alunos, obtendo uma adaptação rápida, gerando interesse e disposição pelos mesmos para continuação do modelo como ferramenta de aprendizagem baseado em problemas, descobertas e estratégias de aprendizagens individualizadas. 
Partindo do intuito de aumentar a motivação dos alunos para como o ensino de Física, o aprendizado tem se tornado um tópico de pesquisa crítico na abordagem da SAI (Aşiksoy, 2018). Sendo utilizada com o objetivo de aprimorar tais motivações, as conquistas de aprendizagem e percepções sobre o ambiente projetado para sua aplicação, os resultados indicam grande satisfação com a utilização da SAI por parte dos alunos, ajudando, portanto, os professores e instrutores a integrar estratégia à abordagem de sala de aula invertida.

Partindo desses conceitos e princípios, o objetivo desse estudo é realizar um mapeamento bem como a compreensão de trabalhos sobre Sala de Aula Invertida (SAI) como suporte ao ensino contemporâneo enquanto método potencialmente significativo para o ensino de Física.

\section{Metodologia}

Nas últimas décadas muitos são os trabalhos que visam mapear um campo dentro da área de estudos da educação em ciência e matemática, nessa direção encontram-se trabalhos na biologia, química e matemática (Nunes et al., 2016; Freitas \& Pires, 2015; Teixeira \& Megid Neto, 2012).

Da mesma forma, estados do conhecimento e estados da arte são comuns no ensino de física, tanto sobre o ensino-aprendizagem na área (Rezende et al., 2009), sobre estratégias didáticas (Macêdo et al. 2013; França \& Siqueira, 2019) quanto sobre conteúdos específicos (Cuesta-Beltrán, 2018). A ideia geral desses estudos é proporcionar ao leitor-pesquisador um panorama da área com avanços e limitações que podem ser pontos de partida para novas investigações, e, em alguns casos, proporcionar ao professor um guia sobre possibilidades didáticas dentro de um campo de estudos.

A pesquisa em questão é um estado do conhecimento, tal como o apontado por Romanowski e Ens (2006). Sendo assim, a primeira etapa da pesquisa foi a definição da base de dados a ser pesquisada.

Optou-se pelo Catálogo de Teses e Dissertações da CAPES, por ser um catálogo que congrega produções oriundas de todas as regiões do Brasil e pelos trabalhos ali disponibilizados apresentarem maior consistência teórico-metodológica. Após essa etapa inicial, o processo de elaboração envolveu as seguintes etapas: a) busca direta através dos descritores na base de dados; b) classificação dos trabalhos segundo descritor, grande área de conhecimento e área de conhecimento; c) seleção baseada em critérios de inclusão e exclusão dos trabalhos selecionados de acordo com o objetivo do trabalho, o ensino de Física.

Conforme já expresso, o universo do trabalho descrito aqui foi composto através dos trabalhos encontrados no Catálogo de Teses e Dissertações da CAPES, sendo a busca realizada no dia 22 de abril de 2020, utilizando como descritor para essa busca somente "sala de aula invertida". Através deste descritor foram obtidos 93 trabalhos para serem analisados, entre teses e dissertações.

Com uma quantidade de trabalhos relativamente grande, foi necessária a utilização de filtros adicionais. Nesta etapa, a classificação do universo do trabalho se deu a partir de filtros definidos através do seguinte conjunto de categorias: i) Grande 
área de conhecimento: multidisciplinar e ciências e da Terra; ii) área de conhecimento: ensino de física, ensino de ciências e matemática e física. Com a utilização dos filtros foram encontrados, no total, 27 trabalhos.

A classificação dos trabalhos foi feita utilizando critérios de inclusão e exclusão onde, após a coleta das teses e dissertações, foi feita uma análise de seus resumos, segundo elementos da análise de conteúdo (Bardin, 2002) visando, fundamentalmente, identificar e caracterizar os textos segundo as categorias definidas a priori. Após a classificação foram obtidos 12 trabalhos relacionados à física e 15 trabalhos relacionados a demais áreas, tais como: biologia, química, matemática e medicina.

Uma vez escolhidos os textos que fariam parte do corpus de análise os mesmos foram submetidos à uma análise mais rigorosa que na primeira etapa. Assim, foram analisados vários componentes do texto, como metodologia, considerações finais, referências. Esse procedimento foi necessário para o aprofundamento da compreensão sobre as teses e dissertações e porque os resumos fornecidos em alguns textos não apresentavam todos os elementos necessários à realização dessa pesquisa.

Adicionalmente, os resumos das dissertações e teses foram analisados com suporte do software Iramuteq 0.7 alfa 2. Para tanto os textos dos resumos das dissertações foram codificados e posteriormente analisado, gerando gráficos de CDH (Classificação Hierárquica Descendente), AFC (Análise Fatorial Confirmatória), Nuvem de Palavras e Grafo de Similitude. Essa etapa visa a emergência de classes que podem corroborar as categorias elencadas em uma primeira etapa do estudo e a comparação entre as dissertações em termos de proximidade lexical. Compreendemos assim como afirmado por Camargo e Justo (2013) que essa ferramenta em si, não exclui a análise realizada pelo pesquisador, no entanto, pode ser uma ferramenta útil na análise qualitativa de dados.

Por trazer esse elemento de análise lexical, portanto, a pesquisa ora aqui apresentada se configura como mista, em que se articula dados quantitativos e qualitativos, com uma interpretação predominantemente qualitativa conforme já defendido por Souza et al. (2020).

Há que se destacar que existem outros levantamentos bibliográficos sobre a SAI dentre os quais destacamos os estudos de Valério e Beletti (2019) que fazem amplo levantamento sobre a SAI a partir do Google Scholar; Gomes et al. (2019) que fazem o levantamento nas dissertações e teses brasileiras, e também Deponti e Bulegon (2018) que fazem o levantamento sobre a SAI particularizando o ensino de física até janeiro de 2018. Diante dessas contribuições anteriores, nota-se que esse estudo para além de trazer dados mais novos utiliza uma metodologia diferenciada, com categorias e instrumentos não trazidos por outros estudos já citados, entre os quais destacamos o uso do software pouco utilizado na pesquisa em ensino de ciências. Assim, esperamos contribuir com a discussão da temática e aprofundar compreensões. 
A seguir apresentamos o fluxograma da pesquisa na figura 1.

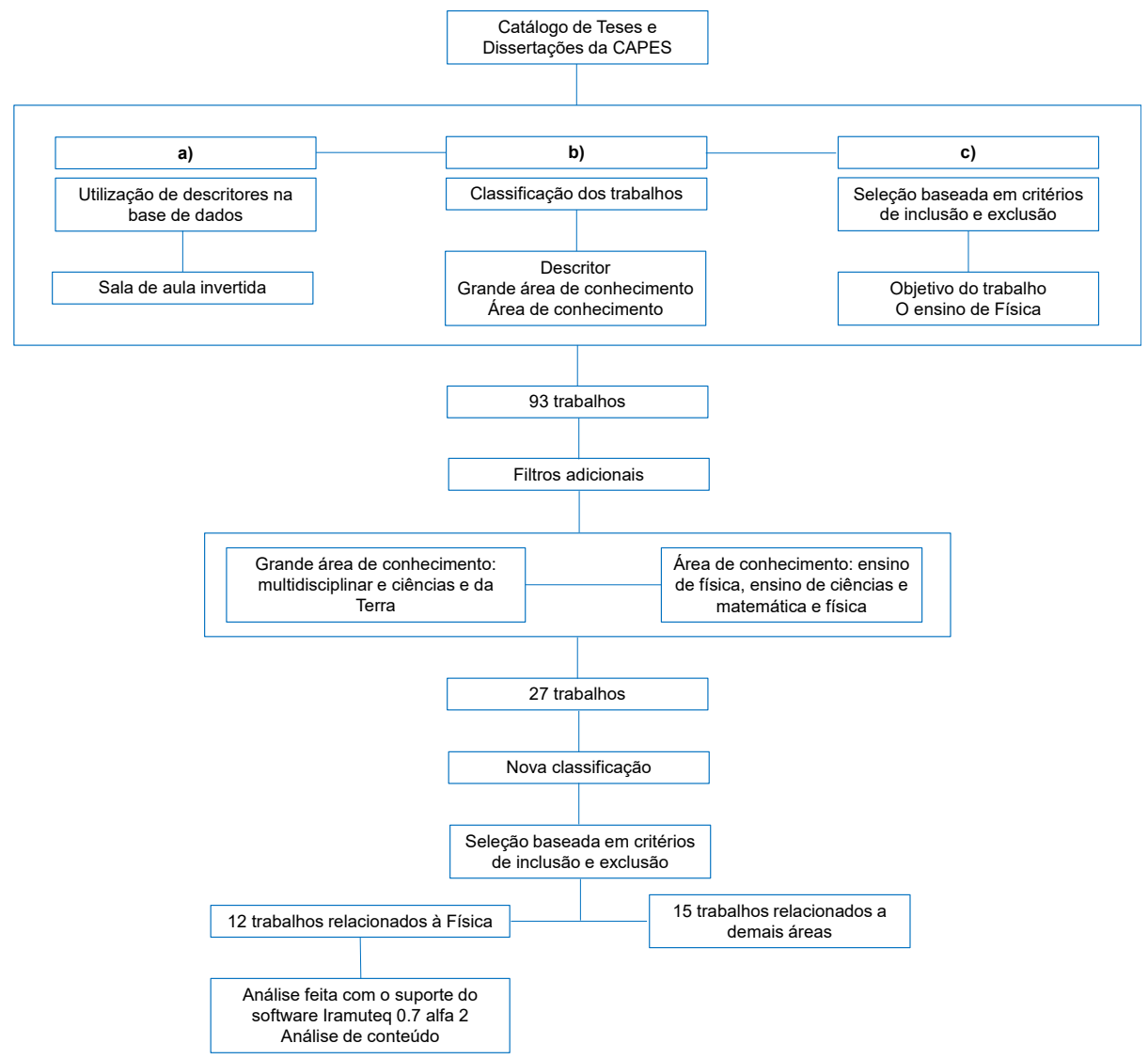

Figura 1. Fluxograma da pesquisa.

Fuente: elaboração pelos autores.

\section{Resultados e discussão}

Por meio dos dados obtidos no Catálogo de Teses e Dissertações da CAPES, a análise de conteúdo dos resumos dos trabalhos encontrados através da classificação dos trabalhos segundo os itens b) e c) contidos na metodologia desse trabalho, foi possível fazer uma análise mais profunda e classificá-los de acordo com: Nível de ensino; Conceitos trabalhados; Referencial teórico - contidos no Quadro 1. 
Quadro 1. Classificação dos trabalhos segundo nível de ensino, conceitos trabalhados e referencial teórico.

\begin{tabular}{|c|c|c|c|c|}
\hline Dissertação/Tese & Código ${ }^{1}$ & $\begin{array}{l}\text { Nível de } \\
\text { ensino }\end{array}$ & $\begin{array}{l}\text { Conceitos } \\
\text { trabalhados }\end{array}$ & Referencial teórico \\
\hline $\begin{array}{l}\text { A metodologia da sala de aula in- } \\
\text { vertida aplicada ao estudo da óptica } \\
\text { geométrica para o ensino médio }\end{array}$ & D1 & $\begin{array}{l}\text { Ensino } \\
\text { Médio }\end{array}$ & $\begin{array}{l}\text { Óptica } \\
\text { geométrica }\end{array}$ & $\begin{array}{l}\text { Wesley Backer; } \\
\text { Nancy Walter- } \\
\text { Perez; Jianyu Dong; } \\
\text { Vygotsky. }\end{array}$ \\
\hline $\begin{array}{l}\text { A percepção dos alunos da } 1^{\mathrm{a}} \text { série } \\
\text { do ensino médio da utilização do } \\
\text { método da flipped classroom no } \\
\text { ensino de física }\end{array}$ & D2 & $\begin{array}{l}\text { Ensino } \\
\text { Médio }\end{array}$ & $\begin{array}{l}\text { Conceitos } \\
\text { em geral }\end{array}$ & $\begin{array}{l}\text { Educacionais de } \\
\text { Piaget e Vygotsky }\end{array}$ \\
\hline $\begin{array}{l}\text { Dispositivo eletrônico semicondutor } \\
\text { LED: uma abordagem baseada em } \\
\text { unidade de ensino potencialmente } \\
\text { significativa }\end{array}$ & D3 & $\begin{array}{l}\text { Ensino } \\
\text { Médio }\end{array}$ & $\begin{array}{l}\text { Física Mo- } \\
\text { derna }\end{array}$ & $\begin{array}{l}\text { Teoria da aprendiza- } \\
\text { gem de Ausubel }\end{array}$ \\
\hline $\begin{array}{l}\text { Levantamento dos requisitos de uma } \\
\text { ferramenta computacional de apoio } \\
\text { à sala de aula invertida }\end{array}$ & D4 & $\begin{array}{l}\text { Ensino } \\
\text { Superior }\end{array}$ & $\begin{array}{l}\text { Conceitos } \\
\text { em geral }\end{array}$ & Apolinário; Morettin \\
\hline $\begin{array}{l}\text { Movimento circular uniforme: apren- } \\
\text { dizagem pelo modelo da sala de aula } \\
\text { invertida (flipped classroom) }\end{array}$ & D5 & $\begin{array}{l}\text { Ensino } \\
\text { Médio }\end{array}$ & $\begin{array}{l}\text { Movimento } \\
\text { circular } \\
\text { uniforme }\end{array}$ & $\begin{array}{l}\text { Alicia Diez, Javier } \\
\text { Tourón e Raúl San- } \\
\text { tiago }\end{array}$ \\
\hline $\begin{array}{l}\text { O uso do software modellus na } \\
\text { formação incial de licenciandos em } \\
\text { física dentro da abordagem meto- } \\
\text { dológica da sala de aula invertida }\end{array}$ & D6 & $\begin{array}{l}\text { Ensino } \\
\text { Superior }\end{array}$ & $\begin{array}{l}\text { Conceitos } \\
\text { em geral }\end{array}$ & Bergmann e Sams \\
\hline $\begin{array}{l}\text { Processos avaliativos reflexivos } \\
\text { integrados a tarefas contínuas no } \\
\text { âmbito do ensino superior em física }\end{array}$ & $\mathrm{T} 1$ & $\begin{array}{l}\text { Ensino } \\
\text { Superior }\end{array}$ & Física I & $\begin{array}{l}\text { Bergmann e Sams, } \\
\text { Schmitz }\end{array}$ \\
\hline $\begin{array}{l}\text { Sequência de atividades didáticas } \\
\text { para uma abordagem fenomenológi- } \\
\text { ca da ondulatória em uma perspecti- } \\
\text { va de sala de aula invertida }\end{array}$ & $\mathrm{T} 2$ & $\begin{array}{l}\text { Ensino } \\
\text { Médio }\end{array}$ & $\begin{array}{l}\text { Oscilações } \\
\text { e Ondas }\end{array}$ & $\begin{array}{l}\text { Bergmann e Sams, } \\
\text { Schmitz }\end{array}$ \\
\hline $\begin{array}{l}\text { Sequência didática híbrida com } \\
\text { mediação digital para o ensino de } \\
\text { óptica física e informação quântica } \\
\text { no ensino médio }\end{array}$ & D7 & $\begin{array}{l}\text { Ensino } \\
\text { Médio }\end{array}$ & Óptica & Vygotsky \\
\hline $\begin{array}{l}\text { Sala de aula invertida com experi- } \\
\text { mentação no ensino da óptica na } \\
\text { educação básica }\end{array}$ & D8 & $\begin{array}{l}\text { Ensino } \\
\text { Médio }\end{array}$ & $\begin{array}{l}\text { Óptica } \\
\text { geométrica }\end{array}$ & $\begin{array}{l}\text { Metodologias Ativas } \\
\text { de Aprendizagem }\end{array}$ \\
\hline $\begin{array}{l}\text { Uma proposta metodológica para o } \\
\text { ensino de conceitos de física media- } \\
\text { da por técnicas do judô e a sala de } \\
\text { aula invertida }\end{array}$ & D9 & $\begin{array}{l}\text { Ensino } \\
\text { Médio }\end{array}$ & $\begin{array}{l}\text { Conceitos } \\
\text { em geral }\end{array}$ & $\begin{array}{l}\text { Teoria da aprendi- } \\
\text { zagem de Ausubel; } \\
\text { Metodologias Ativas } \\
\text { de Aprendizagem }\end{array}$ \\
\hline $\begin{array}{l}\text { Uso de vídeos do youtube e sala de } \\
\text { aula invertida para o ensino do efeito } \\
\text { fotoelétrico }\end{array}$ & D10 & $\begin{array}{l}\text { Ensino } \\
\text { Médio }\end{array}$ & $\begin{array}{l}\text { Efeito fo- } \\
\text { toelétrico }\end{array}$ & Vygotsky \\
\hline
\end{tabular}

Fonte: Dados da pesquisa, 2020.

${ }^{1}$ As dissertações e teses foram codificadas segundo a tipologia do texto. D para dissertação e T para tese, seguindo de um número sequencial para diferenciação. 
A primeira classificação mostrou que a grande maioria dos trabalhos são desenvolvidos para o Ensino Médio (9 trabalhos dos 12 analisados). Ficou claro, ainda, que as temáticas são diversas com uma leve predileção a conteúdos em geral e óptica. No que se refere aos referenciais pode-se destacar a presença de Vygostsky, Bergman e Sams e ainda Ausubel.

Através dessa amostragem, foi possível, também, a distribuição dos trabalhos em Ano; Universidade; Programa e Região - contidos no Quadro 2.

Quadro 2. Distribuição dos trabalhos por ano, universidade, programa e região.

\begin{tabular}{|c|c|c|c|c|}
\hline Código & Ano & Universidade & Programa & Região \\
\hline D1 & 2019 & UESC & MNPEF & Nordeste - Bahia \\
\hline D2 & 2015 & UFES & MNPEF & Sudeste - E. Santo \\
\hline D3 & 2017 & UFABC & MNPEF & Sudeste - S. Paulo \\
\hline D4 & 2018 & $\begin{array}{l}\text { UERN- IFRN - } \\
\text { UFERSA }\end{array}$ & $\begin{array}{l}\text { Programa de Pós-Graduação em } \\
\text { Ensino }\end{array}$ & $\begin{array}{l}\text { Nordeste - Rio } \\
\text { Grande do Norte }\end{array}$ \\
\hline D5 & 2016 & UFAM & MNPEF & Norte - Amazonas \\
\hline D6 & 2015 & UFSCAR & $\begin{array}{l}\text { Programa de Pós-Graduação em } \\
\text { Ensino de Ciências Exatas }\end{array}$ & Sudeste - S. Paulo \\
\hline $\mathrm{T} 1$ & 2018 & UFSM & $\begin{array}{l}\text { Programa De Pós-Graduação em } \\
\text { Educação em Ciências: Química da } \\
\text { Vida e Saúde }\end{array}$ & $\begin{array}{l}\text { Sul - Rio Grande } \\
\text { do Sul }\end{array}$ \\
\hline $\mathrm{T} 2$ & 2017 & UFSM & $\begin{array}{l}\text { Programa De Pós-Graduação em } \\
\text { Educação em Ciências: Química da } \\
\text { Vida e Saúde }\end{array}$ & $\begin{array}{l}\text { Sul - Rio Grande } \\
\text { do Sul }\end{array}$ \\
\hline D7 & 2018 & UNEB & MNPEF & Nordeste - Bahia \\
\hline D8 & 2019 & FURG & $\begin{array}{l}\text { Programa de Pós-Graduação em } \\
\text { Ensino de Ciências Exatas }\end{array}$ & $\begin{array}{l}\text { Sul - Rio Grande } \\
\text { do Sul }\end{array}$ \\
\hline D9 & 2019 & UFAL & $\begin{array}{l}\text { Programa de Pós-Graduação em } \\
\text { Ensino de Ciências e Matemática }\end{array}$ & Nordeste - Alagoas \\
\hline D10 & 2019 & UFGD & MNPEF & $\begin{array}{l}\text { Centro-oeste - Mato } \\
\text { Grosso do Sul }\end{array}$ \\
\hline
\end{tabular}

Fonte: Dados da pesquisa, 2020.

Com essa nova distribuição observar-se que a grande maioria dos trabalhos encontrados foram desenvolvidos através do programa de Mestrado Nacional Profissional em Ensino de Física - MNPEF, o que justificaria o fato da maioria dos trabalhos serem desenvolvidos para o Ensino Médio, já que o MNPEF é um programa de caráter profissional, voltado a professores de ensino médio e fundamental com ênfase de conteúdos na Área de Física.

Na segunda classificação observou-se que a maioria da produção está concentrada nas regiões Sul e Sudeste, isso se dá pelo fato de que há uma concentração da Pós-Graduação no Sul e Sudeste do país, embora o número de polos do MNPEF seja maior no Nordeste, vindo posteriormente o Sudeste e logo em seguida a região Sul.

Mesmo que a maioria dos trabalhos apresentados sejam dissertações, observa-se duas teses que foram acompanhadas pelo mesmo orientador, porém, com perspectivas e elaborações de produtos educacionais diferentes, uma para o 
ensino superior e uma para o ensino médio, mostrando versatilidade do uso da SAI como uma metodologia para o ensino de Física em diferentes níveis, (Pastorio, 2018; Richter, 2017).

Embora a quantidade de trabalhos obtidos tenha sido pequena com relação ao ensino de Física, vale ressaltar que a utilização da metodologia SAI, como ferramenta de ensino, encontra-se em ascensão e vem ganhando espaço já que no ano de 2019 o número de dissertações produzidas corresponde a 48\% das encontradas. Ressaltamos, também, que apesar de uma busca feita através do descritor SAI não se encontra entre os trabalhos os mesmos referenciais, ou seja, isso nos mostra que não existe um padrão de autores citados para o termo pesquisado. Isso é comum quando se trata de uma área nova, não consolidada. Que mesmo sendo um termo atrelado aos trabalhos dos professores norte-americanos Bergmann e Sams (2016), através da publicação de um livro, os próprios autores destacaram que o termo não pertence a nenhum professor ou pesquisador específico. Esta confirmação pode ser vista no Quadro 1, o que nos leva à conclusão de que há uma diversidade de métodos que podem ser caracterizados como formas de inversão da sala de aula, corroborando estudos da literatura (Oliveira, 2016)

Embora nos trabalhos aqui mapeados estejam presentes metodologias e estratégias desenvolvidas para o Ensino de Física, referenciais cognitivistas continuam sendo a principal fundamentação teórica dos pesquisadores, como por exemplo, Ausubel e Vygotsky estão presentes em 50\% dos trabalhos encontrados. Por exemplo, no trabalho de Araújo (2019), utilizando metodologias que levaram em conta plataformas digitais que permitiram uma aprendizagem mais ativa e eficaz, através do método SAI, no estudo da Óptica Geométrica em turmas do $2^{\circ}$ ano do Ensino Médio, a proposta foi aplicada com base nos trabalhos de Baker (2010) e Walter-Perez e Dong (2012), tendo como principal referencial teórico Vygotsky.

A seguir é feita uma breve descrição das dissertações e teses analisadas com a finalidade de proporcionar ao leitor uma visão geral do conteúdo, metodologia e resultados dos trabalhos analisados. As descrições foram organizadas através das características em comum existentes entre os mesmos.

Nível de ensino

Médio

Utilizando o método SAI como uma nova perspectiva de aprendizagem Freitas (2015) elaborou um trabalho utilizando a implementação da flipped classroom para o ensino de conceitos físicos, sendo este aplicado em cinco turmas do $1^{\circ}$ ano do Ensino Médio de uma escola pública. Com o objetivo de compreender as percepções dos alunos e do professor frente a esse método de ensino foi desenvolvido um estudo de caso partindo do princípio de coleta de dados de instrumentos qualitativos (entrevistas e questões abertas) e quantitativos (questões fechadas e a categorização das respostas presentes nas atividades desenvolvidas). O principal resultado foi uma grande eficácia do método, tendo como grande suporte as redes sociais, e que os alunos envolvidos no estudo apresentaram uma dependência considerável da figura do professor para o desenvolvimento das atividades propostas, levando o professor a assumir um papel de mediador na construção do conhecimento. 
Em relação a SAI, através de roteiros elaborados para o ensino do Movimento Circular Uniforme (MCU), para turmas do $1^{\circ}$ ano do ensino técnico integrado com o médio, no Instituto Federal de Educação Ciência e Tecnologia (IFAM) -Campus Manaus Zona Leste, Barbosa (2016) propôs romper a barreira existente entre os alunos sob o ensino tradicional. Na primeira etapa, como objetivo principal, foi mostrado uma explicação ao professor de como seria feito a utilização da ferramenta educacional, EDpuzzle, e a orientação adequada para seus alunos quanto ao uso da mesma; já na segunda parte, considerada a mais importante, teve como fundamental importância a construção de um plano de aula acompanhado de roteiros com possíveis atividades que poderiam ser desenvolvidas em sala de aula, tendo como base teórica a taxonomia de Bloom, ajudando na orientação do educador para definições dos objetivos da aprendizagem e quais seriam as ferramentas tecnológicas fundamentais para atingir os objetivos impostos nas atividades de aprendizagem.

Atrelando o esporte com os conceitos físicos, Filho (2019) traz um trabalho que busca identificar as contribuições da SAI associada a videoaulas por meio das técnicas de judô, proporcionando o ensino-aprendizagem de alguns conceitos gerais da Física em uma turma do ensino médio. Com a utilização da plataforma Google Classroom foram disponibilizados testes e recursos audiovisuais confeccionados para a aplicação da SAI e a construção de conhecimentos nos alunos com ênfase na teoria da aprendizagem significativa de Ausubel. Como resultados obtiveram uma maior interação entre professor-aluno e uma aula diversificada.

\section{Superior}

Destacando a SAI como uma inovação no ensino-aprendizagem, Almeida (2018) observou a dificuldade do professor (facilitador) em acompanhar todo o processo de desenvolvimento das atividades realizadas fora da sala de aula. Objetivando a realização de diagnóstico das práticas e dificuldades encontradas, servindo de base para delimitar os requisitos para um sistema multiagente de apoio à SAI, de acordo com as necessidades dos usuários para correção do problema inerente à implementação dessa teoria da aprendizagem. Tendo como principais fundamentos teóricos Apolinário (2016) e Morettin (2010), o resultado dessa pesquisa foi a criação de um módulo específico para apoiar educadores durante a aplicação da SAI, inserido no moodle.

Diferente da maioria dos trabalhados já citados, Tomanik (2015) utilizou uma turma de licenciandos de Física da Universidade Federal de Uberlândia, utilizando um software de modelagem matemática computacional, o Modellus, tendo como objetivo demonstrar a viabilidade da aplicação da metodologia denominada SAI a partir do desenvolvimento de materiais instrucionais simples e com o emprego de recursos disponíveis à maioria dos professores de Física. Os principais resultados reforçam a viabilidade da SAI e à elaboração de um tutorial em texto cobrindo todo o conteúdo de Física utilizado na experiência.

Conceitos trabalhados

Dentre os conteúdos mais abordados encontra-se o de Óptica e para Vega (2018), com o intuito de promover ainda mais o ensino de Óptica no Ensino Médio, seu objetivo foi propor um produto que contorna as dificuldades existentes no ensino 
de Óptica através do potencial educativo existente nos recursos digitais, da motivação proporcionada pelas recentes aplicações tecnológicas advindas da informação quântica e de novas metodologias educacionais como a SAI.

Com o mesmo intuito de aprimorar o ensino de Óptica, o trabalho de Confortin (2019) relata, analisa e discute a construção e implementação da SAI no ensino da óptica geométrica na Educação Básica. Tendo como resultado a construção de um "Roteiro de aplicação de Sala de Aula Invertida com experimentação no ensino de óptica geométrica" direcionado a professores de Física. A metodologia foi aplicada no $2^{\circ}$ ano do Ensino Médio de uma Escola Estadual situada no interior do Rio Grande do Sul. O material didático contém apresentação teórica, exemplos, exercícios e questões norteadoras de pesquisa que foi enviado aos alunos por uma rede social. Através da aplicação da SAI juntamente com experimentação provocou a aproximação do aluno com o ensino da óptica além de potencializar as interações ocorridas entre aluno-professor.

A Física Moderna, mesmo se tratando de um assunto trabalhado no último ano do Ensino Médio e, muitas vezes, nem visto, também esteve presente nos trabalhos. Santos (2017), por exemplo, elaborou uma sequência didática necessária para explicar o comportamento de materiais semicondutores e o funcionamento do LED. Baseada na teoria da aprendizagem de Ausubel que leva em consideração os conhecimentos prévios que o aluno possui, procurando fornecer um significado relevante sobre a importância do assunto abordado. Dentre várias metodologias, o uso da SAI foi implementado onde o docente oferece ao aluno condições para um estudo fora da sala de aula. O produto educacional foi criado com o intuito de ser aplicado com alunos do $2^{\circ}$ ou $3^{\circ}$ anos do Ensino Médio, mostrando a eficácia da SAI e deixando como uma proposta viável para o preenchimento da falta de material instrucional para o professor que deseja trabalhar de forma inovadora sobre o tema.

Gonçalves (2019) trouxe tal conteúdo como uma forma de ensinar o Efeito Fotoelétrico, abordando o tema de forma didática, é proposto uma sequência didática que utiliza a SAI através de materiais disponíveis no YouTube e em PDF como instrumentos auxiliares para o estudo do conteúdo, tendo como embasamento teórico a teoria de Levi Vygotsky, pautando a interatividade como forma de contribuição na aprendizagem.

\section{Análise textual apoiada no Iramuteq}

Como procedimento adicional à análise já expressa anteriormente foi realizada uma análise que traz elementos da análise de conteúdo de Bardin (2002) porém tendo como suporte o software de análise textual IRAMUTEQ (Interface de R pour les Analyses Multidimensionnelles de Textes et de Questionnaires).

Na Figura 2 temos a sugestão de emergência de seis classes no discurso dos doze trabalhos analisados. Ao se fazer a análise nota-se que as classes 2, 4, 5 e 6 apresentam proximidade lexical e, portanto, foram incorporadas em uma única categoria de análise que corresponde a $65,9 \%$ dos segmentos de texto. A essa categoria deu-se o nome de "Definição e características". No dendrograma (figura 2) nota-se a existência de uma classe bem distante lexicalmente das demais (Classe 3), essa classe 
foi incorporada à categoria "Metodologia de Pesquisa", com 17,7\% dos segmentos de texto. E a classe 1 foi incorporada à categoria "Meios de Ensino" com 16,5\% dos segmentos de texto classificados.

\begin{tabular}{|c|c|c|c|c|c|c|c|c|c|c|c|}
\hline Palavra & $x^{2}$ & Palavra & $x^{2}$ & Palavra & $x^{2}$ & Palavra & $x^{2}$ & Palavra & $x^{2}$ & Palavra & $x^{2}$ \\
\hline desenvolvimento & 21,46 & invertido & 15,24 & processo & 22,19 & método & 27,70 & médio & 38,76 & abordar & 26,80 \\
\hline etapa & 14,48 & sala & 13,47 & realizar & 16,88 & flipped & 14,69 & óptico & 32,97 & assunto & 26,80 \\
\hline característica & 14,48 & através & 12,92 & parte & 15,68 & classrrom & 14,69 & ano & 36,80 & estudar & 21,12 \\
\hline análise & 14,48 & casa & 12,92 & aula & 12,92 & ensino & $12,89 \mathrm{t}$ & turma & 23,88 & vídeo & 15,68 \\
\hline desenvolvido & 14,20 & metodologia & 12,54 & aluno & 12,13 & objetivo & 7,24 & ensino & 23,37 & conteúdo & 13,49 \\
\hline estudante & 12,24 & aula & 11,80 & aprendizagem & 10,87 & aprendizagem & 5,03 & geométrico & 21,39 & possuir & 10,5 \\
\hline atividade & 11,42 & objetivo & 9,60 & sala & 6,71 & construção & 4,58 & experimentação & 15,83 & tema & 7,36 \\
\hline constante & 9,48 & aplicação & 9,22 & roteiro & 5,72 & aplicar & 4,58 & educação & 15,83 & ponto & 7,36 \\
\hline questionário & 9,48 & experiência & 8,59 & professor & 3,84 & & & básico & 10,50 & conhecimento & 5,79 \\
\hline pesquisa & 8,18 & resultado & 7,27 & & & & & produto & 7,36 & além & 5,72 \\
\hline didático & 6,54 & digital & 4,61 & & & & & físico & 6,54 & & \\
\hline sequência & 6,54 & dever & 4,61 & & & & & conceito & 5,72 & & \\
\hline instrumento & 5,12 & universidade & 4,61 & & & & & ativo & 5,72 & & \\
\hline perceber & 5,12 & texto & 4,61 & & & & & implementação & 5,72 & & \\
\hline teste & 5,12 & denominar & 4,61 & & & & & educacional & 5,31 & & \\
\hline \multirow[t]{2}{*}{ propiciar } & 5,12 & necessidade & 4,61 & & & & & trabalho & 4,62 & & \\
\hline & & & & & & & & sair & 3,89 & & \\
\hline
\end{tabular}

Figura 2. Dendrograma com classes obtidas no Iramuteq.

Fuente: elaboração pelos autores.

A primeira categoria "Definição e características" agrega os segmentos de texto que se encontram principalmente na área central da análise fatorial acima. Percebase que as cores (mesmas do dendrograma) demonstram a proximidade fatorial das palavras o que corrobora a decisão de considerar essas classes como componentes de uma mesma categoria. Essencialmente os segmentos de texto versam sobre a definição e características da SAI como compreendida em cada trabalho. As duas outras categorias apresentam aspectos metodológicos do ponto de vista da pesquisa realizada (Metodologia de Pesquisa) e da proposta de ensino (Meios de Ensino).

Vale salientar que grande parte dos textos analisados são fruto de mestrados profissionais e como afirmado por Damiani et al. (2013) as pesquisas de intervenção pedagógica devem descrever os métodos de pesquisa e os métodos de ensino separados, daí provavelmente as duas categorias que emergem diante das classes do dendrograma eAnálise Fatorial Correspondência. Há que se notar também que segundo os autores algumas pesquisas são erroneamente classificadas como pesquisa-ação.

Outro tipo de pesquisa muito comum nas dissertações de mestrado profissional é a pesquisa-ação. Também nesse caso se justifica a emergência de duas classes ligadas a metodologia, uma vez que nas pesquisas do tipo ação, segundo Tripp (2005) existem as etapas de intervenção e avaliação do processo de intervenção. 
Por fim, temos as figuras 3 e 4 (Nuvem de palavras e Grafo de similitude).

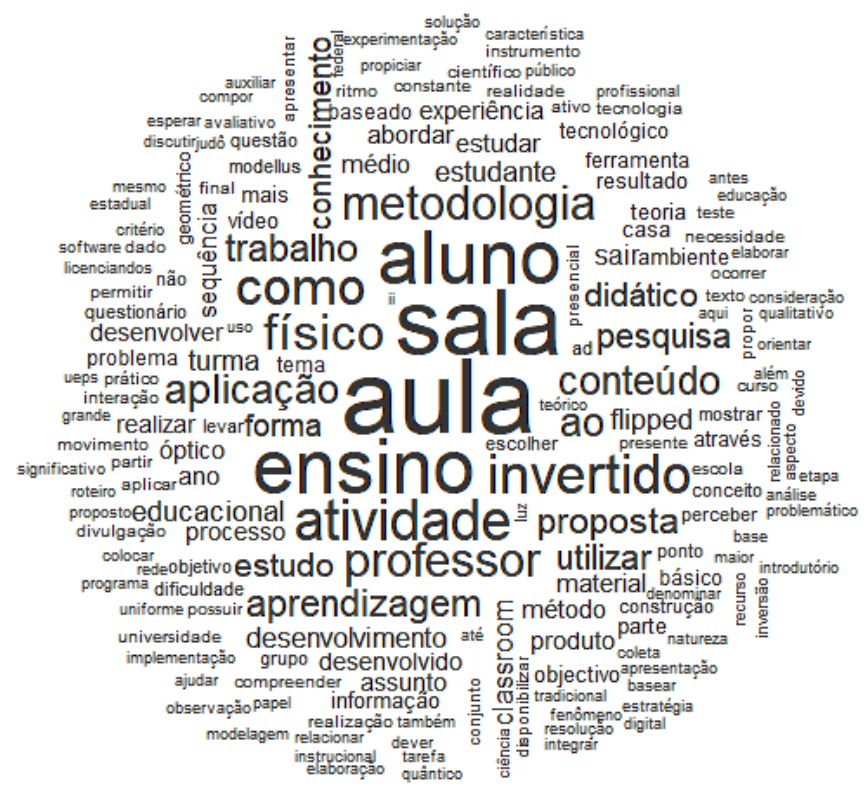

Figura 3. Nuvem de palavras.

Fuente: elaboraça própia.

Ainda que a nuvem de palavras tenha pouca informação quando comparada à $\mathrm{CHD}$ e AFC, essa traz a confirmação das categorias encontradas anteriormente. Em que a SAI, a Metodologia de Ensino e o foco no aluno são encontrados entre as palavras de maior frequência. Ao passo que a Figura 4 nos traz um grafo de similitude traz informações que podem ser adicionadas para a compreensão.

Podemos perceber que a SAI é, como esperado, o tema central, mas que existem informações adicionais nas outras extremidades. Nota-se que a palavra professor encontra-se secundarizada à palavra aluno, o que é também um bom indício de que a ênfase se dá no aluno e não no professor. Porém, há que se destacar que a a palavra ensino aparece com grande destaque e que a palavra aprendizagem não aparece. Há aqui uma contradição. Como falar de ensino, ainda mais com uma metodologia ativa e não ter foco na aprendizagem? Essa informação parece indicar que parte das dissertações tem como foco o processo voltado muito mais ao professor (ensino) do que ao processo mais ligado ao aluno (aprendizagem). Essa inferência pode indicar uma dicotomia não desejada na abordagem das questões escolares com a SAI, pois há muito pesquisadores alertam que não se pode separar o ensino da aprendizagem (Kubo \& Botomé, 2001). Dado que hoje não se concebe a separação entre os dois fenômenos, mesmo para a investigação, torna-se preocupante que os conceitos estejam em espaços distintos. Outra informação relevante quando se trabalha o grafo de similitude dos textos é que as pesquisas relatadas apresentam forte relação com sequencias didáticas, sendo proposições de como implementar a SAl em um contexto de prática. 


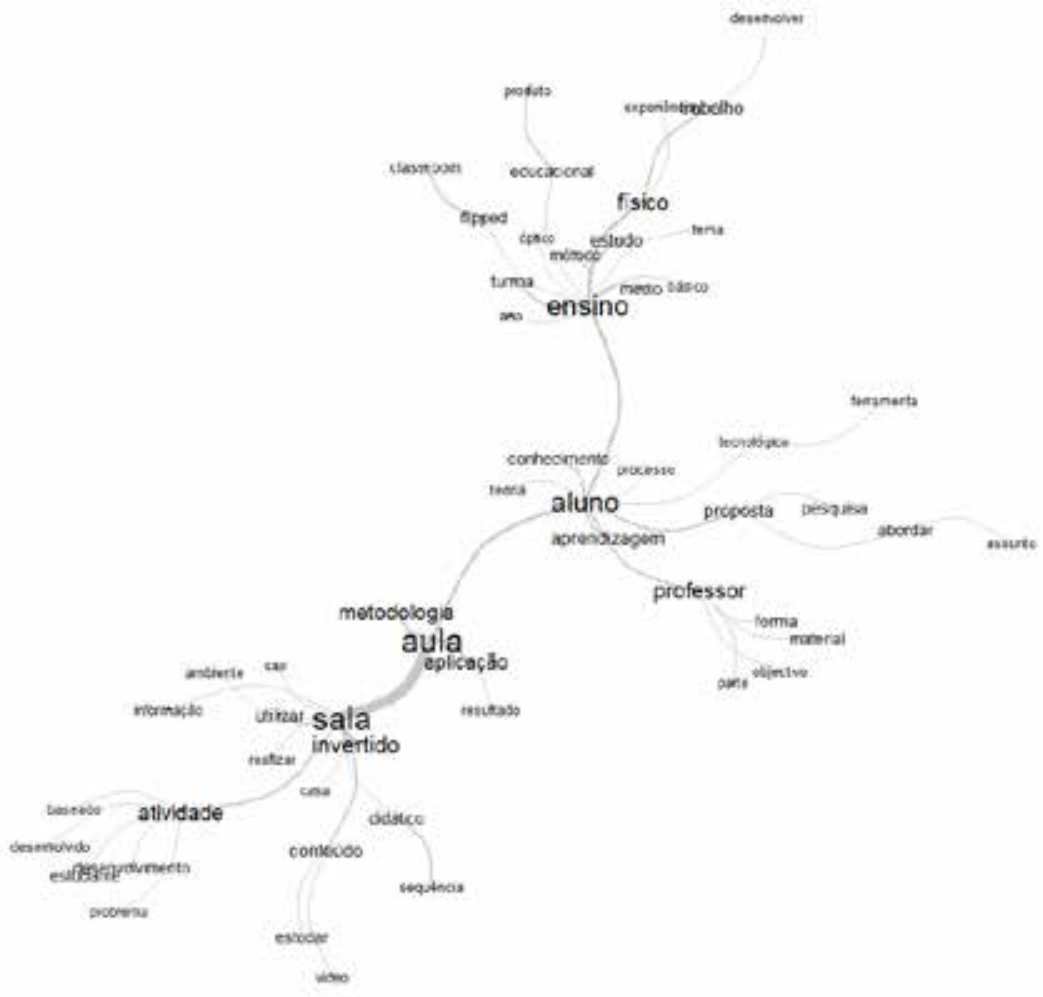

Figura 4. Gráfico de similitude.

Fuente: elaboraça própia.

\section{Considerações finais}

Com o intuito de compreender os avanços nas pesquisas em SAI, na qual a própria lógica da organização das atividades de ensino-aprendizagem é invertida e na qual a aquisição do conhecimento tornar-se-ia mais apropriada para os tempos atuais, neste trabalho buscamos, através de dissertações e teses existentes no periódico CAPES, analisar as características e contribuições dos trabalhos de pós-graduação stricto sensu.

No decorrer desta produção, que é um estado do conhecimento, foram obtidos doze textos que abordavam a estratégia da SAI no ensino de Física. Observa-se que ainda há uma lacuna de produções sobre essa temática, já que a busca foi feita em uma plataforma que agrega toda a produção nacional. Essa ausência se faz notar principalmente quando se trata em conteúdos já que a maior parte da produção se concentrou na Óptica, conteúdos gerais e Física Moderna. Porém, mesmo assim, a ideia metodológica nos permite compreender melhor, e com mais coesão, o uso da SAI como uma verdadeira proposta para o ensino de Física, possuindo, então, grande potencialidade de aplicações e rendimentos, nos mostrando confiabilidade tanto por parte dos educadores como dos educandos. 
Através das classificações feitas, destaca-se que grande parte da produção desenvolvida é realizada por professores do ensino básico através do programa de Mestrado Nacional Profissional em Ensino de Física (MNPEF), o que nos possibilita averiguar uma grande procura em desenvolver produtos educacionais que possam ajudar e serem desenvolvidos em salas de aulas com suas perspectivas de ensino e condições existentes. É importante ressaltar que a maioria da produção existentes concentra-se nas regiões Sul e Sudeste, mesmo o Nordeste possuindo uma maior concentração de polos do MNPEF.

Os resultados demonstram que a implementação das atividades desenvolvidas nas teses e dissertações, sendo elas no Ensino Médio ou Superior, foram promotoras de grande satisfação, o que nos faz perceber a necessidade de ajustes no ensino tradicional. Nota-se, no decorrer das leituras, que a principal finalidade, por partes dos professores, seria na aplicação das atividades, deixando um pouco de lado o processo de compreender de maneira fundamentada a aprendizagem dos alunos e a eficácia dos estudos com base no desenvolvimento através dos referenciais teóricos, mesmo sendo discutido um forte indício de pesquisas de intervenção pedagógica com ênfase nas questões em dois grupos de interesse de investigação: um primeiro que visa compreender o ensino e outro que visa compreender a aprendizagem baseada na estratégia.

Ressaltamos, pelo atual momento que a educação se encontra, que a SAI possui grande relevância para o Ensino de Física, tornando-se imprescindível para o desenvolvimento de novas estratégias e produtos educacionais para o ensino, sendo ele em Física ou em outras áreas. Que, tal implementação, pode possibilitar grandes progressos e resultados na aprendizagem com grandes embasamentos teóricos, possibilitando, assim, melhores compreensões no processo ensino-aprendizagem por partes dos professores e estudantes.

\section{Referências}

Almeida, L. M. B. de (2018). Levantamento dos requisitos de uma ferramenta computacional de apoio à sala de aula invertida (Dissertação de Mestrado, Universidade Federal Rural do SemiÁrido; Universidade do Estado do Rio Grande do Norte; Instituto Federal do Rio Grande do Norte, Mossoró, Brasil).

Apolinário, F. (2016). Metodologia da Ciência: filosofia e prática da pesquisa. 2. ed. São Paulo: Cengage Learning.

Araújo, J. C. (2019). A metodologia da sala de aula invertida aplicada ao estudo da óptica geométrica para o ensino médio. (Dissertação de Mestrado, Universidade Estadual de Santa Cruz, Ilhéus, Brasil)

Aşıksoy, G. (2018). The effects of the gamified flipped classroom environment (GFCE) on students' motivation, learning achievements and perception in a physics course. Quality \& Quantity, 52(S1), 129-145.

Aşiksoy, G. \& Özdamli, F. (2015). Flipped Classroom adapted to the ARCS Model of Motivation and applied to a Physics Course. Eurasia Journal of Mathematics, Science \& Technology Education, 12, 1589-1603.

Bacich, L. \& Moran, J. (2018). Metodologias ativas para uma educação inovadora: uma abordagem teórico-prática. Porto Alegre, Brasil: Penso Editora. 
Baker, J.W. (2015b). The classroom flip: Using web course management tools to become the guide by the side. https://bit.ly/3ChgzyB; https://bit.ly/3pq1x5Q

Barbosa, P. C. P. (2016). Movimento circular uniforme: aprendizagem pelo modelo da sala de aula invertida (flipped classroom). Dissertação de Mestrado, Universidade Federal doAmazonas

- UFAM, Brasil) https://bit.ly/2ZdNIIL

Bardin, L. (2002). Análise de conteúdo. Lisboa Edições 70.

Berbel, N. (2011). As metodologias ativas e a promoção da autonomia de estudantes. Semina: Ciências Sociais e Humanas, 32(1), 25-40.

Bergmann, J. \& Sams, A. (2016). Sala de aula invertida: uma metodologia ativa de aprendizagem. (Tradução Afonso Celso da Cunha Serra). $1^{\mathrm{a}}$ ed., Rio de Janeiro, Brasil: LTC.

Camargo, B., Justo, A., (2013). IRAMUTEQ: um software gratuito para análise de dados textuais. Temas em Psicologia, 21(2), 513-518.

Confortin, C. K. Cl. (2019). Sala de aula invertida com experimentação no ensino da óptica na educação básica (Dissertação de Mestrado, Universidade Federal do Rio Grande, Santo Antônio da Patrulha, Brasil)

Cuesta-Beltrán, Y. (2018). Estado del arte: tendencias en la enseñanza de la física cuántica entre 1986 y 2016. Tecné Episteme y Didaxis: TED, 44, 11-17.

Damiani, M. F., Rochefort, R. S., de Castro, R. F., Dariz, M. R. \& Pinheiro, S. S. (2013). Discutindo pesquisas do tipo intervenção pedagógica. Cadernos de Educação, 45(1), 57-67.

Deponti, M. A. M. \& Bulegon, A. M. (2018). Uma revisão de literatura sobre o uso da metodologia sala de aula invertida para o ensino de física. Vidya, 38(2), 103-118.

Filho, R. B. dos S. (2019). Uma proposta metodológica para o ensino de conceitos de física mediada por técnicas do judô e a sala de aula invertida (Dissertação de Mestrado, Universidade Federal de Alagoas, Maceió, Brasil)

Fisch, K. (2010, April 19). Transparent algebra: Homework [Blog post]. https://bit.ly/3BdTyeB

França, S. \& Siqueira, M. (2019). Propostas didáticas no ensino de física para deficientes visuais: análise de trabalhos em periódicos e eventos nacionais (2000 -2018). Lat. Am. J. Phys. Educ, 13(4), 1-8.

Freitas, A. \& Pires, C. (2015). Estado da Arte em educação matemática na EJA: percursos de uma investigação. Ciência \& Educação, 21(3), 637-654.

Freitas, V. J. de (2015). A percepção dos alunos da $1^{a}$ série do ensino médio da utilização do método da flipped classroom no ensino de física (Dissertação de Mestrado, Universidade Federal do Espírito Santo, Vitória, Brasil)

Gomes, A. L., Brettas, A. C. F. \& Marques, W. (2020). A Sala de aula invertida na pós-graduação brasileira: uma análise das produções entre 2015 e 2019. Research, Society and Development, 9(12), e28991211192-e28991211192.

Gonçalves, S. A. (2019). Uso de vídeos do Youtube e da sala de aula invertida para o ensino do efeito fotoelétrico (Dissertação de Mestrado, Universidade Federal da Grande Dourados, Dourados, Brasil)

Kubo, O. \& Botomé, S. (2001). Ensino-aprendizagem: uma interação entre dois processos comportamentais. Interação em Psicologia, 5(1). https://doi.org/10.5380/psi.v5i1.3321

Macêdo, J., Pedroso, L., Voelzke, M. \&Araújo, M. (2014). Levantamento das abordagens e tendências dos trabalhos sobre as Tecnologias de Informação e Comunicação apresentados no XIX Simpósio Nacional de Ensino de Física. Caderno Brasileiro de Ensino de Física, 31(1), 11-25.

Mazur, E. (2015). Peer instruction: a revolução da aprendizagem ativa. Bookman.

Morán, J. (2015). Mudando a educação com metodologias ativas. Coleção mídias contemporâneas. Convergências midiáticas, educação e cidadania: aproximações jovens, 2(1), 15-33.

Morettin, L. G. (2010). Estatística básica: probabilidade e inferência. São Paulo: Pearson Prentice Hall. 
Nunes, A., Dantas, J., Oliveira, Ó. \& Hussein, F., (2016). Revisão no Campo: O Processo de EnsinoAprendizagem dos Conceitos Ácido e Base entre 1980 e 2014. Química Nova na Escola, 38(2), 185-196

Oliveira, T. (2016). Sala de aula invertida (flipped classroom): Inovando as aulas de física. Física na Escola, 14(2), 4-13.

Pastorio, D. P. (2018). Processos avaliativos reflexivos integrados a tarefas contínuas no âmbito do ensino superior em física (Tese de Doutorado, Universidade Federal de Santa Maria, Santa Maria, Brasil).

Rezende, F., Ostermann, F. \& Ferraz, G., (2009). Ensino-aprendizagem de física no nível médio: o estado da arte da produção acadêmica no século XXI. Revista Brasileira de Ensino de Física, 31(1), 1-8.

Richter, S. S. (2017). Sequência de atividades didáticas para uma abordagem fenomenológica da ondulatória em uma perspectiva de sala de aula invertida (Tese de Doutorado, Universidade Federal de Santa Maria, Santa Maria, Brasil)

Romanowski, J. \& Ens, R., (2006). As pesquisas denominadas do tipo "Estado da Arte". Diálogos Educacionais, 6(6), 37-50.

Santos, S. C. do E. (2017). Dispositivo eletrônico semicondutor led: uma abordagem baseada em unidade de ensino potencialmente significativa (Dissertação de Mestrado, Universidade Federal do Abc, Santo André, Brasil)

Şengel, E. (2014). Using the 'flipped classroom' to enhance physics achievement of the prospective teacher impact of flipped classroom model on physics course. Journal of the Balkan Tribological Association, 20(3), 488-497.

Souza, F. C. S., Nunes, A. O. \& Oliveira, M. A. (2020). O programa de pós-graduação em educação profissional e tecnológica e a formação humana integral: análise da produção acadêmica no IFRN/Mossoró. Revista Brasileira da Educação Profissionale Tecnológica, 2(19), https:// doi.org/10.15628/rbept.2020.11629.

Suhr, I. (2016). Desafios no uso da sala de aula invertida no ensino superior. Revista Transmutare, 1(1), 4-21.

Teixeira, P. M. M. \& Neto, J. M. (2012). O estado da arte da pesquisa em ensino de Biologia no Brasil: um panorama baseado na análise de dissertações e teses. Revista Electrónica de Enseñanza de las Ciencias, 11(1). https://bit.ly/3E5jLOm

Tomanik, M. (2015). O uso do software modellus na formação incial de licenciandos em física dentro da abordagem metodológica da sala de aula invertida (Dissertação de Mestrado, Universidade Federal de São Carlos, São Carlos, Brasil)

Tripp, D., (2005). Pesquisa-ação: uma introdução metodológica. Educação e Pesquisa, 31(3), 443-466.

Valério, M. \& Beleti, C. R. (2019). Caracterização da produção acadêmica brasileira sobre a sala de aula invertida. Revista Actio, 4(3), 17-34.

Vega, L. F. L. (2018). Sequência didática híbrida com mediação digital para o ensino de óptica física e informação quântica no ensino médio (Dissertação de Mestrado, Universidade do Estado da Bahia, Salvador, Brasil).

Walter-Perez, N. \& Dong, J. (2012). Flipping the classroom: How to embed inquiry and design projects into a digital engineering lecture, in Proceedings of the American Society for Engineering Education (ASEE) PSW Section Conference. San Luis Obispo, CA. https://bit.ly/3vxRtJ4

\section{Como citar em APA:}

Silva, J. D., Oliveira, A. \& Oliveira, A (2021). A produção do conhecimento sobre sala de aula invertida no ensino de Física: um olhar sobre a pós-graduação brasileira. Revista Iberoamericana de Educación, 87(2), 123-138. https://doi.org/10.35362/rie8724577 